\title{
Using artificial intelligence technologies for sustainable development
}

\author{
Anton Nazarov ${ }^{1, *}$, Denis Kovtun ${ }^{1}$, and Stefan Talu ${ }^{2}$ \\ ${ }^{1}$ Ural State University of Economics, Yekaterinburg, Russia \\ ${ }^{2}$ The Technical University of Cluj-Napoca, Cluj-Napoca, Romania
}

\begin{abstract}
Artificial intelligence as a simulator of human behavior and thinking emerged as a result of machine learning. Through AI, they recognize and interpret data, on the basis of which programs of various types of activities are subsequently built. The rapid introduction of artificial intelligence-based technologies into the economic and social spheres of the international community has not been left out of the United Nations ' view from the point of view of using the capabilities of digital computers to solve problems at the level of intelligent beings in order to achieve the goals of sustainable development. The article discusses the specific aspects of I, the application of which will make the process of achieving the SDGs more effective and of high-quality.
\end{abstract}

\section{Introduction}

All devices that work based on artificial intelligence have a number of typical features: they are autonomous, able to exchange data, because they have a cyber-physical system that perceives and transmits information, learn from experience, require a minimum of physical support, adapt well to the external environment, are inanimate structures with the skills of self-awareness, analysis, generalization of information, development of intelligent solutions $[1, \mathrm{p} .202]$.

The scope of artificial intelligence is very wide:

- agriculture: determination of the most favorable periods for planting and harvesting operations;

- aviation: support the damaged aircraft until it reaches the landing zone;

- education: providing an individual approach to each student;

- economics: market analysis and forecast;

- robotics: minimizing machine errors;

- web development and IT technologies: taking into account user preferences in the face of rapid resource changes; data-based machine learning and modeling [2, $\mathrm{p}$. 400];

- medicine: real-time access to data on the state of human health, the ability to quickly respond to changes in the body;

- transport: self-driving cars;

\footnotetext{
*Corresponding author: nazarovad@usue.ru
} 
- trade: studying the needs and behavior of customers in order to improve service;

- jurisprudence: drafting of transactions, statements of claim [5, p. 20];

- security of the state and the population: face recognition in order to track the location of subjects dangerous to society, identification of a specific individual by analyzing the heartbeat and gait; the use of unmanned aerial vehicles, underwater robots in the military;

- assistance to people with physical disabilities (simplified text input into digital devices), elderly individuals (stress reduction with the help of robotic domestic "cats" and " $\operatorname{dogs} »)$;

- search and rescue operations: aerial photography of disaster zones;

- film industry: creating photorealistic effects.

\section{Methods and materials}

The fundamental goal of improving and developing the abilities of digital computers to perform actions similar to the actions of intelligent beings is to increase the level of wellbeing and quality of life of people, to ensure law and order and the security of the society.

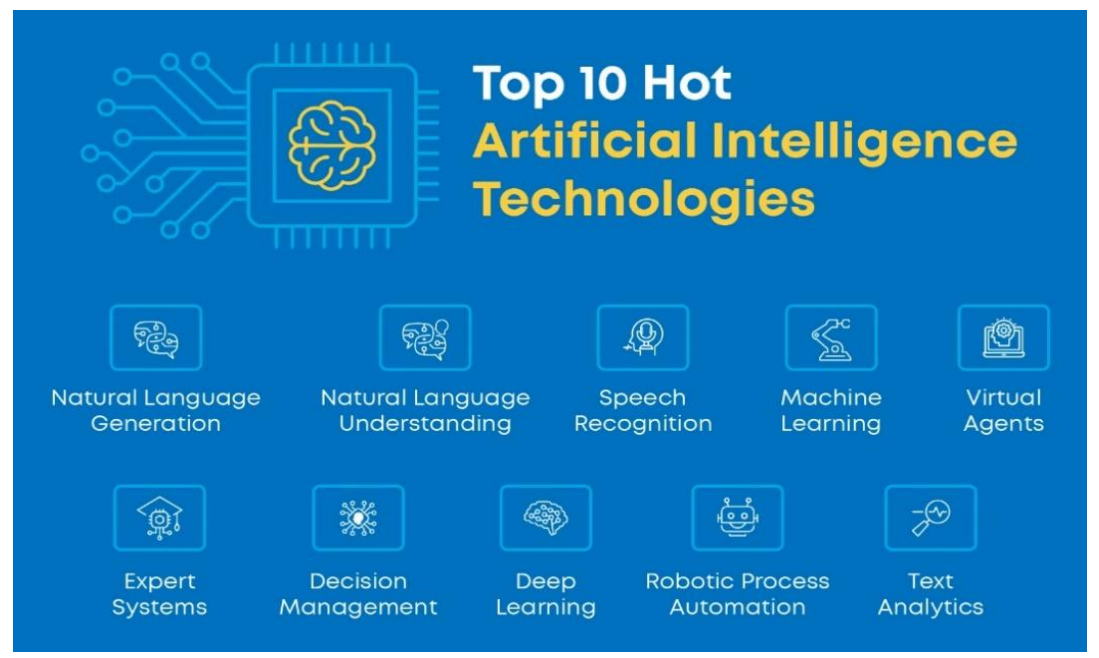

Fig. 1. TOP 10 artificial intelligence technologies

The economic and social spheres are the priority areas for the development of the properties of intelligent systems to perform creative functions that were previously characteristic of humans.

The key tasks of implementing artificial intelligence in the economy include: improving the quality of planning and forecasting; automating template manipulations; using devices that do not require support from external factors; ensuring a high level of labor safety; forming a positive attitude and emotional attachment to certain products in the consumer; creating optimal models for personnel selection and training [4, p.5].

In social terms, the fundamental tasks of developing digital computer skills are considered to be: improvement of medical and educational services, the quality of services provided by state and municipal authorities; reduction of costs for the functioning of state management structures.

For the successful development of artificial intelligence technologies, jobs are created at a high level of productivity, competitive conditions are provided for the work of specialists 
in the field of training computers to perform tasks at the level of human activity, and the export of AI-based products is supported.

\section{Results and discussions}

There are already certain standards that allow us to assess the success of policies for the introduction of intelligent systems that perform creative functions in public life. The criteria for success are called: 1) a systematic increase in the number of enterprises that are among the industry leaders that implement technologies based on the capabilities of artificial intelligence, as well as authorities at various levels that actively use AI technologies in their work; 2) the level of digitalization of public services.

The initial assessment of the results of the introduction of artificial intelligence in the economic and social spheres revealed the need to improve the level of mathematical and natural science education, combine it with social and humanitarian training, improve AIbased software, and improve the availability and quality of data [8, p.104].

Taking into account all the possibilities and prospects of artificial intelligence, we can talk about the possibility of its positive contribution to the achievement of the sustainable development Goals set by the United Nations.

Innovative engineering and technological solutions based on the ability of digital computers to solve problems of the level of human intelligence should be considered from the point of view of the main dimensions that characterize sustainability - economic, social and environmental.

The economic component implies the improvement of the economic sphere of human activity, the social - social development and equality of all individuals, the environmentalreasonable consumption of natural resources, environmental protection, saving it for future generations.

Within the framework of achieving the economic goals of sustainable development, the use of the ability of intelligent systems to perform creative actions at the human level is possible to identify and predict, through machine algorithms, the most problematic regions with a low level of human well-being; fight poverty, lack of food with the help of network technologies that do not require external control; help socially vulnerable individuals in the form of a fair distribution of resources; application of forecasting systems to prevent officials from using their powers of authority, trusted rights; risk management in medicine, agriculture; collection, application, analysis of huge amounts of data intended for the preventive prediction of man-made and natural disasters; implementation of IoT in "smart" megacities to prevent epidemics; improvement of personalized social services based on data from social networks and wearable devices; support of mass media engaged in the promotion of healthy lifestyle; development of precision medicine.

It should be taken into account when achieving the Sustainable Development Goals that the economic and social opportunities of different countries and regions of the world are very different. It is necessary to adapt the implementation of artificial intelligence to the specifics of each particular state, to identify alternative ways to achieve the SDGs, including through rapidly developing digital technologies. It is also important to take into account the consequences of the coronavirus pandemic, which has negatively affected the aspects of the Sustainable Development Goals related to improving the health of nations [6, p.261].

The UN calls artificial intelligence a fundamental tool in achieving the SDGs, which allows us to radically change the paradigm of business models and countries ' policies based on sustainability. At the same time, the international organization emphasizes: AI cannot successfully solve non-standard situations that require such moral human qualities as mercy, a sense of duty, love, and justice. The international community is also considering other risks 
and threats associated with the active introduction of digital computers into the life of a civilization that solve problems of the level of human intelligence.

\section{Conclusions}

Scientists involved in the development of AI, already warn of the danger of extreme types of intelligence that does not have significant features of human personality, poorly controlled, aimed at creating a world without people, call for immediate legal regulation of this field of scientific activity.

Adherents of the other point of view, who support the requirements of legislative regulation of the introduction of AI into society, believe that this process will not cause much harm to people if specialists learn to overcome the damage that age and disease cause to the human body, to indefinitely prolong the life of the body and the brain as a part of it, thus making the process of expanding consciousness A complete redesign of the brain will radically improve it, reorganize the process of cognition, allow people to develop faster than super intelligent machines. That is why the world community is now investing a lot of money in the development of nanotechnology, biotechnology, and artificial intelligence technologies [7, p. 62].

Much attention is paid to research on the specifics of human-robot interaction, which, according to scientists, will help solve a number of global problems, for example, during search and rescue operations in a radiation-contaminated environment or under water, in surgery and even in everyday life.

The use of reliable and effective artificial intelligence in all sectors of the world community ensures a purposeful movement towards achieving the sustainable Development Goals due to the acceleration of the implementation of technological solutions developed and implemented on its basis.

The main task of the world community in the framework of the development of artificial intelligence technologies is the need to use its capabilities for the benefit of both entire states and individual individuals.

\section{References}

1. H. Brink, D. Richards, M. Feverolf, Machine Learning, 336 (Series "Programmer's Library", 2017)

2. D. Brockman, What We Think About Machines That Think: The World's Leading Scientists About Artificial Intelligence, 552 (2017)

3. N. Bostrom, Artificial Intelligence. Stages. Threats. Strategies (2016)

4. O.E. Goryacheva, O.A. Evstigneeva, V.V. Sidorov, International Student Scientific Bulletin, 4 (2018)

5. V. A. Zhilkin, Journal of Foreign Law and Comparative Law, 5(72), 16 (2018)

6. O. O. Samsonovich, E.A. Fokina, Int. J. of Applied and Basic Research, 5-1, 257 (2018)

7. V.V. Potopakhin, Romance of Artificial Intelligence, 170 (2017)

8. A.S. Harlanov, Economics and Entrepreneurship, 1(114), 103 (2020)

9. J. He, S.L. Baxter, J. Xu, J. Xu, X. Zhou, K. Zhang, Nature Medicine, 25(1), 30 (2019)

10. W. Jia, Y. Li, R. Qu, T. Baranowski, L.E. Burke, H. Zhang,... ... M. Sun, Public Health Nutrition, 22(7), 1168 (2019)

11. S. Lee, Q. Shi, C. Lee, APL Materials, 7(3), (2019)

12. T.P. Mashamba-Thompson, E.D. Crayton, Diagnostics, 10(4) (2020) 
13. V. Partel, S. Charan Kakarla, Y. Ampatzidis,. Computers and Electronics in Agriculture, 157, 339 (2019)

14. S. Qiu, Q. Liu, S. Zhou, C. Wu, Applied Sciences (Switzerland), 9(5), (2019)

15. J. Singh, K. Flaherty, R.S. Sohi, D. Deeter-Schmelz, J. Habel, K. Le Meunier-FitzHugh, V. Onyemah, Journal of Personal Selling and Sales Management, 39(1) (2019)

16. P. Wang, J. Yao, G. Wang, F. Hao, S. Shrestha, B. Xue, Y. Peng, Science of the Total Environment, 693 (2019)

17. Q. Wang, P. Lu, International Journal of Pattern Recognition and Artificial Intelligence, 33(5), (2019)

18. I. Zacharov, R. Arslanov, M. Gunin, D. Stefonishin, A. Bykov, S. Pavlov, M. Fedorov, Open Engineering, 9(1), 512 (2019)

19. L. Zhao, T. Dai, Z. Qiao, P. Sun, J. Hao, Y. Yang, Process Safety and Environmental Protection, 133, 169 (2020) 